\title{
Stress Fracture of the Pubic Ramus in a Female Long Distance Runner: A Case Report
}

\author{
Seçkin Şenışık, Metin Ergün \\ Ege University Faculty of Medicine, Department of Sports Medicine, Izmir, Turkey
}

\begin{abstract}
Stress fractures are overuse injuries of the bone caused by continuous repetitive submaximal stress over time. They constitute $0.7-20 \%$ of all sports injuries and are mainly seen in tibia, metatarsal bones and fibula. Pelvic stress fractures are rare (1-2\%) and mostly seen in female long distance runners. Common complaints are groin, hip and thigh pain increasing with weight bearing activities.

A 41 years old recreational female runner was admitted to the clinic with chronic groin pain lasting for about eight months. She was performing running training on hard surfaces at high intensity for a long time and firstly she was admitted to the Orthopaedic and Traumatology clinic with groin pain. MR images have shown non-displaced fracture of the right ischium. There has been no relief with medication and rest, then the athlete was admitted to another clinic. X-ray and bone scintigraphy confirmed fracture line at the right superior pubic ramus and right ischium. Blood analysis has revealed low level of $25-\mathrm{OH}$ vitamin D (13 ng/ml). Vitamin D3 supplementation has been prescribed for three months, and then the athlete has started $1 \mathrm{~km}$ daily slow running trainings. Due to exacerbation of pain during running, athlete was admitted to our clinic. Physical examination revealed normal posture and range of motion, and there were no swelling, inflammation and neurological signs and symptoms. As pelvis MRI and CT images confirmed healing, and 25$\mathrm{OH}$ vitamin $\mathrm{D}$ level returned to normal limits, the athlete has then started trainings. Training volume has been increased gradually. Full recovery was achieved at the end of the third month, as there were no complaints during daily activities and training.

Stress fractures of the pelvis should be included in the differential diagnosis of female distance runners who have prolonged groin pain increasing with exercise. Detailed medical history, physical examination, blood tests, and radiological images are keys to reach certain diagnosis. Treatment plan should include risk factor analysis and progressive training programs.
\end{abstract}

Keywords: Athlete, pelvic stress fracture, $25-\mathrm{OH}$ vitamin D

Available at: http://journalofsportsmedicine.org and http://dx.doi.org/10.5152/tjsm.2017.072

Cite this article as: Senisik S, Ergün M. Stress fracture of the pubic ramus in a female long distance runner: A case report. Turk J Sports Med. 2017;52:70-6.

Geliş Tarihi / Date Received: 27.01.2017. Kabul Tarihi / Date Accepted: 15.02.2017. Yayın Tarihi / Published Online: 20.07.2017. Yazışma Adresi / Corresponding Author: Seçkin Şenışık, Ege University Faculty of Medicine, Department of Sports Medicine, İzmir, Turkey. Email: seckinsnsk@gmail.com

C2017 Türkiye Spor Hekimleri Derneği. Tüm hakları saklıdır. 


\section{Kadın Uzun Mesafe Koşucusunda Pubik Ramus Stres Kırığı: Olgu Sunumu}

\section{öz}

Stres kırığı, tekrarlayan submaksimal yüke bağlı olarak kemiklerde gelişen aşırı kullanım yaralanmasıdır. Tüm spor yaralanmalarının \%0.7-20'sini oluşturur ve en sık tibia, metatarsal kemikler ve fibulada görülür. Pelvisin stres kırıkları tüm stres kırıklarının ancak \%1-2'sini oluşturur ve daha çok kadın uzun mesafe koşucularında görülmektedir. Şikayetler sıklıkla kasık, kalça veya uylukta ağrı şeklinde ortaya çıkmakta ve yük bindiren fiziksel aktiviteler ile şiddetlenmektedir.

Rekreasyonel uzun mesafe koşucusu kadın sporcu (41 yaş) yaklaşık sekiz aydır devam eden kronik kasık ağrısı şikayeti ile kliniğimize başvurmuştur. Sert zeminde uzun süre ve yüksek şiddette koşu antrenmanları yapan sporcunun, ilk olarak Ortopedi ve Travmatoloji kliniğine başvurduğu ve yapılan kalça MRı tetkiki sonucunda sağ iskiumda nondeplase kırık saptandığı anlaşılmıştır. İstirahat ve ilaç tedavisine yanıt vermemesi üzerine ikinci bir sağlık kuruluşuna başvuran sporcunun, burada yapılan X-Ray ve tüm vücut kemik sintigrafisinde sağ superior pubik ramus ile sağ iskiumda kırık hattı tanımlanmıştır. Aynı merkezde yapılan kan biyokimyası tetkikinde $25-\mathrm{OH}$ vitamin D düzeyi düşük olarak saptanan $(13 \mathrm{ng} / \mathrm{ml})$ sporcuya D3 vitamini takviyesi başlanmıştır. Sporcu, yaklaşık üç aylık destek tedavisi sonrasında günde 1 km'lik yavaş koşu antrenmanlarına başlamış, ancak koşu sırasında tekrar ağrı hissetmesi üzerine kliniğimize başvurmuştur. Fizik muayenesinde postür ve eklem hareket açıkığı normaldi, ağrı bölgesinde ödem veya kızarıklık yoktu ve nörolojik bulguları negatifti. Pelvis MRI ve BT tetkikleri sonucunda iyileşmesi normal olarak değerlendirilen sporcunun replasman tedavisine devam edilmesi ile $25-\mathrm{OH}$ vitamin $\mathrm{D}$ düzeyi normale döndü. Şikayetlerinin kaybolması üzerine antrenmanlara başlatılan sporcunun koşu mesafesi ve şiddeti kademeli olarak arttırıldı. Takip eden üç ay süresince koşu sırasında ve günlük aktivitelerde şikayeti olmayan sporcuda klinik olarak tam iyileşme sağlandı.

Pelvisin stres kırıkları özellikle uzun süren ve egzersizle artan kasık ağrısı olan kadın mesafe koşucularında ayırıcı tanıda düşünülmelidir. Ayrıntılı tıbbi öykü ve fizik muayenenin yanı sıra uygun tetkiklerle tanı kesinleştirilmeli ve tedavi programı düzenlenirken risk faktörleri göz önünde bulundurulmalıdır. Klinik düzelme oldukça kademeli olarak arttırılan antrenman programları ile spora dönüşs sağlanmalıdır.

Anahtar Sözcükler: Sporcu, pelvis stres kırığı, 25-OH vitamin D

\section{GíRiş}

Stres kırığı kemiklerde tekrarlayan submaksimal yüke bağlı olarak gelișen aşırı kullanım yaralanmasıdır (1). Kemik tarafından tolere edilen maksimum güçten daha düşük bir güce tekrarlayıcı șekilde maruz kalınması, kemik yapısında bozulmaya neden olmakta ve kısmi veya tam kırık ortaya çıkabilmektedir (2). Stres kırıkları tüm spor yaralanmalarının \%0.7-20'sini oluşturmaktadır ve en sık tibia, metatarsal kemikler ve fibulada görülmektedir (3). 
Koşucuların diğer sporculara göre daha yüksek stres kırığı insidansına sahip oldukları ve \%13-37'sinde stres kırığı görülebildiği bilinmektedir. Kadınlarda stres kırıklarına daha fazla rastlandığı (3) ve erkekler ile benzer antrenman yapan kadınlarda stres kırığı gelişme riskinin 1.2-10 kat fazla olduğu bildirilmiștir (4).

Pelvisin stres kırıkları nadirdir ve tüm stres kırıklarının ancak \%1-2'sini oluştururlar (5). Pelviste stres kırıklarının en sık yerleşim yeri iskiopubik ramustur. Sıklıkla simfizise yakın bölgede inferior pubik ramus etkilenir (6). Bu tür stres kırıkları özellikle kadın uzun mesafe koşucularında görülmektedir $(6,7)$.

\section{OLGU}

Uzun mesafe koşucusu 41 yaşındaki kadın sporcu (164 cm, $50 \mathrm{~kg})$, sekiz aydır devam eden kronik kasık ağrısı şikayeti ile kliniğe başvurmuştur. Rekreasyonel olarak yaklaşık on yıldır koşu antrenmanları (ilk 5 yıl, haftada 4-5 gün, 3-5 km koşu) yapan sporcu, son beș yıldır yarı maraton (21 km) koşularına katılmakta ve haftada üç gün ortalama $10 \mathrm{~km}$ ve haftada bir gün 20 km'yi bulan koşu antrenmanları yapmaktadır. Sporcu koşu antrenmanları dışında bașka bir egzersiz yapmamaktadır. Başlangıçta sadece antrenman sonrasında ortaya çıkan kasık ağrısı zamanla yürüme, çömelme, oturma ve kalkma gibi günlük aktivitelerde de kısıtlanmaya neden olmuştur. İstirahat etmesine rağmen şikayetleri azalmayınca ilk olarak Ortopedi ve Travmatoloji kliniğine başvurmuş ve kas yaralanması tanısıyla kas gevşetici ve antienflamatuar ilaçlar ile tedavi önerilmiştir. İlaç kullandığı bu dönemde antrenmanlara başlamış ve 5 km'lik bir yarışa katılmıştır. Bu yarışın sonuna doğru tekrar ağrı hisseden, ancak yarışı tamamlayabilen sporcu, bir hafta sonra yarı maratona katılmış ve şikayetleri artış göstermiştir. Yarış sonrası yürüyüşü de kısıtlanmaya başlamıştır. Bunun üzerine aynı merkezde kontrol muayenesi sonrası olgunun sağ kalça MRI tetkikinde sağ iskiumda nondeplase kırık tespit edilmiş (Şekil 1) ve istirahat önerilmiştir.

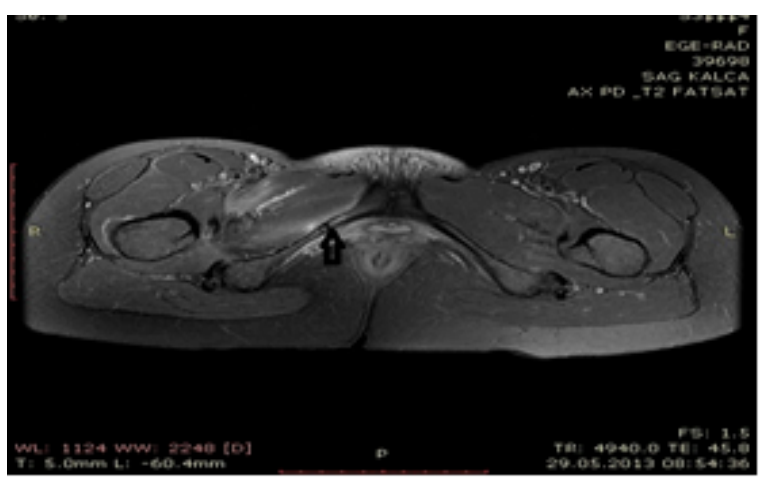

Şekil 1. Kalça MRI tetkikinde sağ iskionda nondeplase fraktür hattı

Şikayetlerinin devamı üzerine ikinci bir sağllk kuruluşuna başvuran sporcunun, sağ kalça X-ray tetkikinde superior ve inferior pubik ramuslarda kırık hattı (Şekil 2) ve tüm vücut kemik sintigrafisinde (Şekil 3) sağ superior pubik ramus ile sağ iskiumda kırığa sekonder opasite artışı gözlenmiştir. İstirahat önerilen ve aylık periyotlarla kontrole çağrılan sporcunun çekilen kontrol grafisinde (Şekil 4) kırık hattının devam ettiğinin görülmesi üzerine tekrarlanan MRI tetkikinde (ilk MRI tetkikinden dört ay sonra) (Şekil 5) bulgularda belirgin regresyon saptanmıştır. Ağrı şikayetinde de azalma olması nedeniyle sporcu yavaş koşulara başlatılmış, ancak on gün içinde tekrar ağrı hissetmesi üzerine koşuları bırakmıştır. Bu dönemde yapılan kan biyokimyası tetkikinde 25-OH vitamin D düzeyi düşük saptanmış (13 ng/ml) ve 
günde 1200 mg kalsiyum ile 800 IU D3 vitamini takviyesi başlanmıştır. Yaklaşık üç aylık destek tedavisi sonrasında çekilen kontrol grafisi (Şekil 6) sonucunda kırığın iyileşmekte olduğu bildirilerek sporcu günde 1 km'lik yavaş koşu antrenmanlarına tekrar başlatılmıştır.

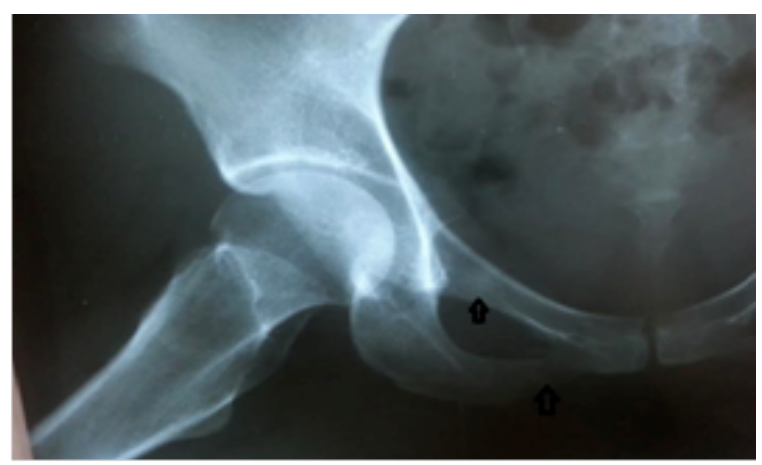

Şekil 2. Sağ kalça X-ray tetkikinde superior ve inferior pubik ramuslarda kırık hattı

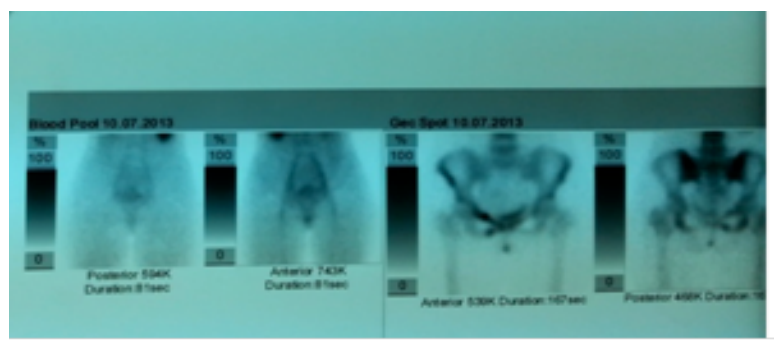

Şekil 3. Trifazik kemik sintigrafisinde sağ superior pubik ramus ile sağ iskiumda fraktüre sekonder opasite artışı

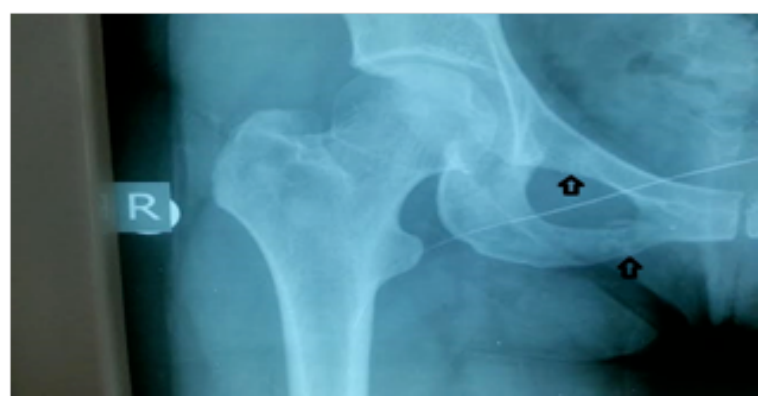

Şekil 4. Sağ kalça X-ray tetkikinde superior ve inferior pubik ramuslarda kırık hattı

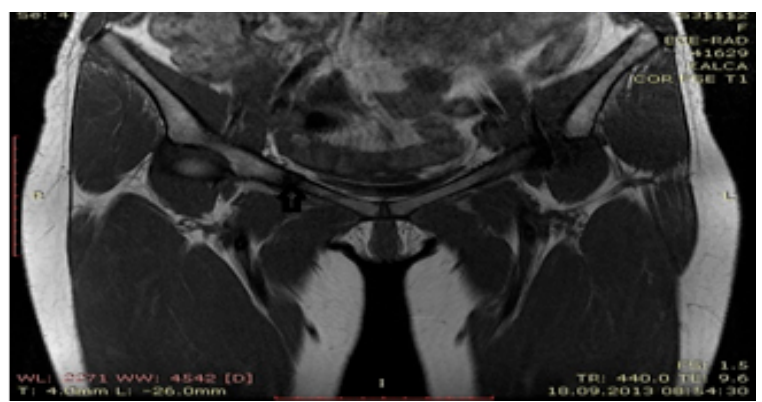

Şekil 5. Pelvis MRI tetkikinde bulgularda belirgin düzeyde regresyon

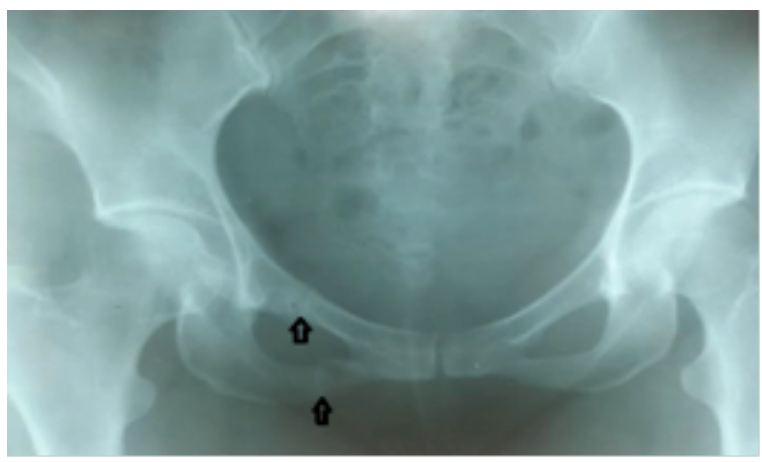

Şekil 6. Nötral pelvis X-ray tetkikinde superior ve inferior pubik ramuslarda kırık hattında iyileşme bulguları

Koşu sırasında tekrar ağrı hissetmesi üzerine şikayetlerinin başlangıcından yaklaşık sekiz ay sonra kliniğimize başvurdu. Fizik muayenesinde postür ve kalça eklem hareket açıklığı normal bulundu, ağrı bölgesinde ödem veya kızarıklık görülmedi ve nörolojik bulgu saptanmadı. Yapılan pelvis MRI tetkikinde (Şekil 7) kemik yapılar normal olarak değerlendirildi ve pelvis BT istendi (Şekil 8).

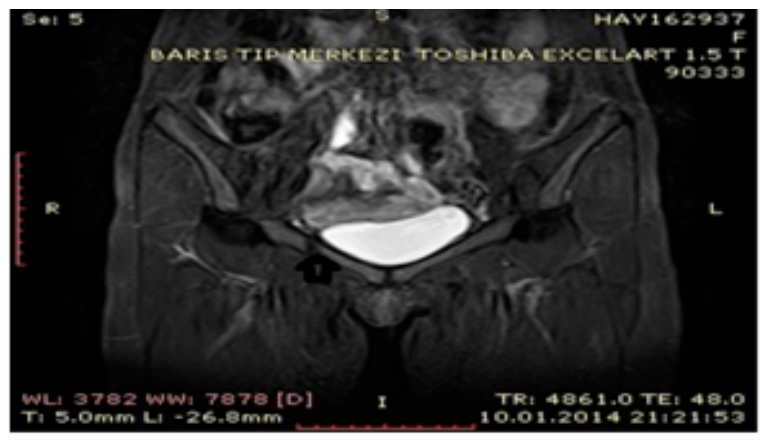

Şekil 7. Normal pelvis MRI bulguları 


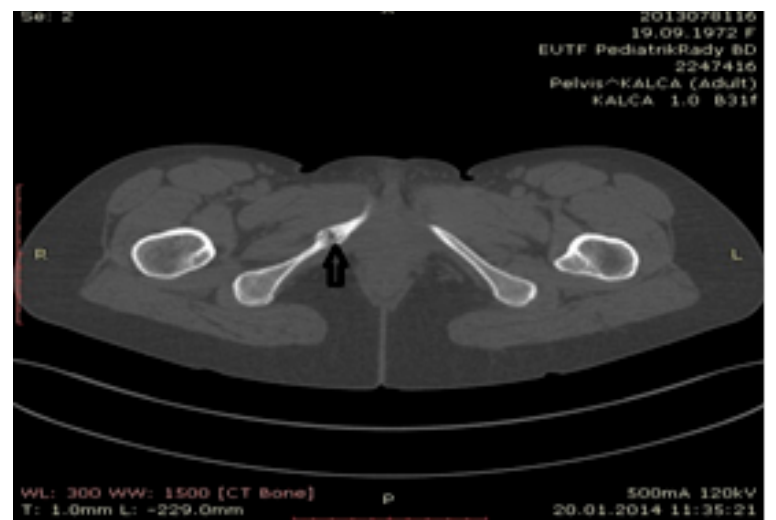

Şekil 8. Pelvis BT tetkikinde eski fraktür bulguları

BT sonucunda eski kırığa ilişkin bulgular saptandı. İyileşme süreci normal olarak değerlendirilen sporcuya öncelikle istirahat önerildi, birinci ayın sonunda ilk hafta $1 \mathrm{~km}$ yürüyüş ve $1 \mathrm{~km}$ koşu şeklinde antrenman programı düzenlendi. Her hafta $1 \mathrm{~km}$ arttırlarak bir ay sonunda $5 \mathrm{~km}$ yürüyüş ve $5 \mathrm{~km}$ hafif tempolu koşu mesafesine çıkıldı. Daha sonra yürüyüş mesafesi kısaltılan sporcunun koşu mesafesi sabit tutularak temposu arttırıldı. Sporcunun üç ay sonra yapilan tetkikinde $25-\mathrm{OH}$ vitamin D düzeyinin $(34.1 \mathrm{ng} / \mathrm{ml})$ normale döndüğü görüldü. Kontrol X-ray tetkikinde (Şekil 9) kırık bulgularının tam olarak düzeldiği saptanan sporcunun koșu temposu ve mesafesi yaralanma öncesi düzeye çıkarıldı. Takip eden üç ay süresince koşu sırasında ve günlük aktivitelerde şikayeti olmayan sporcuda klinik olarak tam iyileşme sağlandığı kanaatine varıldı.

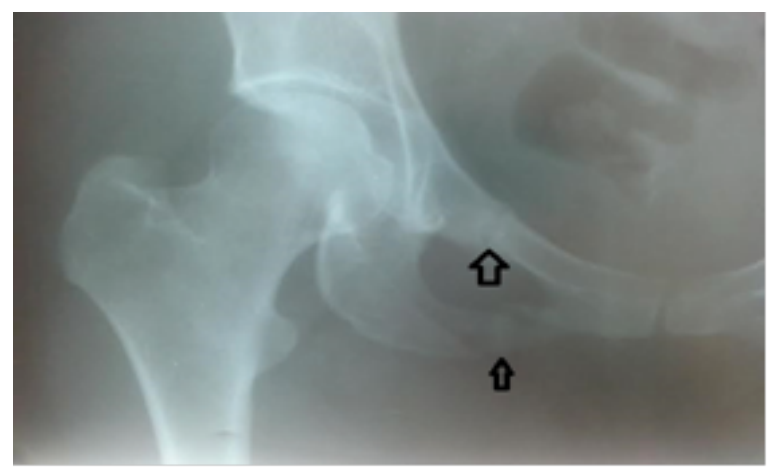

Şekil 9. Sağ kalça X-ray tetkikinde kallus bulguları

\section{TARTIŞMA}

Pelvisin stres kırıkları nadirdir ve daha çok kadın uzun mesafe koşucularında görülmektedir $(6,7)$. En slk yerleşim yeri ischiopubik ramustur ve çoğunlukla simfizise yakın bölgede inferior pubik ramus etkilenir (6). Şikayetler daha çok kasık, kalça veya uylukta ağrı şeklinde ortaya çlkmakta (5-7) ve yük bindiren fiziksel aktiviteler ile şiddetlenirken, istirahat ile azalmaktadır. Fizik muayenede pubik ramus üzerinde derin palpasyonda lokal hassasiyet (6), ağrılı ve sınırlı abdüksiyon ve dirençli addüksiyon ile ağrıda artış olabilir. Benzer muayene bulguları nedeniyle adduktor kas zorlanması ve osteitis pubis ile sıklıkla karıştırılabilir $(4,8)$. Bu olguda da stres kırığı ilk olarak kasık ağrısı şikayetine neden olmuştur. Adduktor kas zorlanması tanısıyla tedavi planlanmış ve şikayetlerin geçmemesi üzerine yapilan tetkikler sonucunda pelvis stres kırığı tanısına ulaşılmıştır.

Stres kırıklarının konservatif tedavisi fizyoterapi, soğuk uygulama, nonsteroid antienflamatuvar (NSAİ) ilaç kullanımı ve aktivite modifikasyonu ile ağrı kontrolünü içermektedir. Ağrı eşiğinin altındaki aktivitelerde yük vermeye izin verilmek-tedir. İstirahat ve yürüyüş sırasında ağrı varsa geçici olarak koltuk değnekleri kullanımı ile yükten kurtarma önerilebilir. Yüzme, havuz egzersizleri, eliptik ve statik bisiklet gibi direkt yükün azaltıldığı aktiviteler ile kuvvet ve kondisyon korun-maya çalışılır (2). Fiziksel aktiviteye dönüşe ise kademeli olarak izin verilmektedir. Lokal kemik hassasiyeti düzeldikten bir hafta sonra sporcu koşu hızının ve mesafesinin yarısı ile aktiviteye başlayabilir. Antrenman için gerekli mesafe koşulabildiğinde hiz arttırılabilir (2). Bu olguda, tam iyileşme sağlanmadan spora dönüş nedeniyle üç 
defa ağrı nüksü ve günlük aktivite kısıtlılığı ile karşılașılması, spora dönüş antrenman programının düzenlenmesinin önemine dikkat çekmektedir.

Stres kırıkları ile ilişkili risk faktörleri olarak yaș, antrenman süre ve şiddeti, zemin, ayakkabı ve beslenmeye ilişkin faktörler, sigara ve alkol kullanımı, aşırı kullanım yaralanması öyküsünün yanı sıra amenore ve hipotalamik disfonksiyon gibi hormonal değişiklikler bildirilmektedir $(9,10)$. Bacak uzunluk farkl, ayağın yüksek longitudinal arkı ve genu varum gibi bazı biyomekanik faktörlerin de stres kırıkları ile ilişkisi olduğu bilinmektedir (9). Tedavi programları düzenlenirken stres kırığına neden olabilecek risk faktörleri göz önünde bulundurulmalıdır. Bunlar stres kırıklarından korunmada olduğu kadar tedavinin başarısı için de önem taşırlar. Bu olguda, risk faktörleri açısından antrenman içeriği, zemin, beslenme, menstrüel siklusları sorgulandı ve detaylı fizik muayene yapıldı. Ayrıca metabolik değerlendirme amacıyla kan biyokimyası testleri yapıldı. Bu değerlendirmeler sonucunda pelvis stres kırığl oluşumunda sporcunun uzun süre yüksek şiddette ve uzun mesafe koşu antrenmanları yapması ve $25-0 H$ vitamin D eksikliğinin rolü olabileceği düşünüldü.

Stres yaralanmaları ile ilgili çalışmalarda koşu mesafesi arttıkça yaralanma oranında artış olduğu gösterilmiştir (9). Koşu mesafesi ve hızındaki ani artışlar gibi antrenman programındaki hızlı değişiklik-ler yaralanma riskini arttırabilmektedir. Bu olguda da sürekli olarak sert zeminde uzun mesafe koşuları yapılmasına bağlı aşırı kullanım sonucunda stres kırığı gelişmiş olabilir.

Beslenme yetersizliği de stres kırıklarının oluşumunda önemli bir risk faktörü olarak göz önünde bulundurulmaktadır. Kalsiyum ve D vitamini, kemik sağlığını korumak ve geliştirmek için gerekli beslenmenin önemli iki bileșeni olarak kabul edilmektedir. Kadın sporcular ve askerlerde yapılan çalışmalarda elde edilen bulgular günde 1500 mg'dan fazla kalsiyum tüketenlerde stres kırığı riskinin daha az olduğunu göstermektedir $(11,12)$. Myburgh ve ark. mesafe koşucularında yaptıkları vaka-kontrol çalışmasında günlük kalsiyum alımının yetersiz olmasının düşük kemik mineral yoğunluğuna neden olduğunu ve stres kırığı riskini arttırdığını göstermişler-dir (13). Nieves ve ark. 18-26 yaş aralığında-ki yarıșmacı kadın mesafe koşucularında yaptıkları prospektif çalışmada kalsiyum, $\mathrm{D}$ vitamini ve protein alımındaki artışın kemik mineral yoğunluğundaki artış ve stres kırıklarından korunma ile ilişkili olduğunu göstermişlerdir (12). Günde 800 mg'dan az kalsiyum tüketen kadınlarda 800-1500 mg arası kalsiyum tüketenlere oranla iki kat, 1500 mg'dan fazla kalsiyum tüketen kadınlara oranla da yaklaşık altı kat daha fazla kırık riski bulunmuştur. Lappe ve ark. da kadın askerlerde yaptıkları çalışmada, $2000 \mathrm{mg}$ kalsiyum ve 800 IU D vitamini tüketenlerde stres kırıkları insidansının \%20 daha düşük olduğunu göstermişlerdir (11). Bu olguda da D vitamini eksikliği önemli bir risk faktörü olarak görülebilir. Stres kırığı olan kadın koşucunun D vitamini düzeyinin düşük olması, uzun süren şikayetlerin D vitamini desteğinden sonra giderek azalması ve $\mathrm{D}$ vitamini düzeyinin normale dönmesi ile birlikte şikayetlerin ortadan kalkması bu düşünceyi desteklemektedir. Olgunun tedavi sürecindeki gelişmeler önceki çalışmaların sonuçları ile uyum göstermektedir. Kalsiyum ve D vitamini desteği ile hem stres kırığı riski azaltılabilmekte, hem de mevcut kırıkların daha hızlı iyileşmesi sağlanabilmektedir. 


\section{SONUÇ}

Uzun süren ve egzersizle artan kasık ağrısı şikayeti olan kadın mesafe koşucularında pelvisin stres kırığı ayırıcı tanıda göz önünde bulundurulmalıdır. Ayrıntılı tıbbi öykü ve fizik muayenenin yanı sıra, uygun tetkiklerle tanı kesinleştirildikten sonra tedavi programı düzenlenirken, stres kırığına neden olabilecek risk faktörleri göz önünde bulundurulmalıdır. Bunlar stres kırıklarından korunmada olduğu kadar tedavinin başarısı için de önem taşırlar. Klinik düzelme oldukça, kademeli olarak arttırılan antrenman programları ile spora dönüş sağlanmalıdır.

\section{KAYNAKLAR}

1. Boden BP, Osbahr DC. High-risk stress fractures: evaluation and treatment. J Am Acad Orthop Surg. 2000;8(6):344-53.

2. Fredericson M, Jennings F, Beaulieu C, et al. Stress fractures in athletes. Top Magn Reson Imaging. 2006;17(5):309-25.

3. Brukner P, Bradshaw C, Khan KM, et al. Stress fractures: a review of 180 cases. Clin J Sport Med. 1996;6(2):85-9.
4. Zeni A, Street CC, Dempsey RL, et al. Stress injury to the bone among women athletes. Phys Med Rehabil Clin N Am. 2000;11(4):929-47.

5. Lapp JM. Pelvic stress fracture: assessment and risk factors. J Manipulative Physiol Ther. 2000;23(1):52-5.

6. Noakes TD, Smith JA, Lindenberg G, et al. Pelvic stress fractures in long distance runners. Am J Sports Med. 1985;13(2):120-3.

7. Hill PF, Chatterji S, Chambers D, et al. Stress fracture of the pubic ramus in female recruits. J Bone Joint Surg Br. 1996;78(3):383-6.

8. Miller C, Major N, Toth A. Pelvic stress injuries in the athlete: Management and prevention. Sports Med. 2003;33(13):1003-12.

9. Bennell KL, Malcolm SA, Thomas SA, et al. Risk factors for stress fractures in track and field athletes. A twelve-month prospective study. Am J Sports Med. 1996;24(6):810-8.

10. Feingold D, Hame SL. Female athlete triad and stress fractures. Orthop Clin North Am. 2006;37(4): 575-83.

11. Lappe J, Cullen D, Haynatzki G, et al. Calcium and vitamin D supplementation decreases incidence of stress fractures in female navy recruits. J Bone Miner Res. 2008;23(5):741-9.

12. Nieves JW, Melsop K, Curtis M, et al. Nutritional factors that influence change in bone density and stress fracture risk among young female cross-country runners. PM R. 2010;2(8):740-50.

13. Myburgh $\mathrm{KH}$, Hutchins J, Fataar $\mathrm{AB}$, et al. Low bone density is an etiologic factor for stress fractures in athletes. Ann Intern Med. 1990;113(10):754-9. 